\title{
Nebulised amiloride in respiratory exacerbations of cystic fibrosis: a randomised controlled trial
}

I M Bowler, B Kelman, D Worthington, J M Littlewood, A Watson, S P Conway, $S$ W Smye, S L James, T A Sheldon
Patients and methods

Patients were recruited from patients attending the Leeds cystic fibrosis clinic at St James's University Hospital (children) and Seacroft Hospital (adults). They had classical features of cystic fibrosis and two measurements of sweat sodium and chloride concentrations of greater than $60 \mathrm{mmol} / \mathrm{l}$.

All patients admitted for a course of inpatient intravenous antibiotic treatment were eligible for inclusion into the study unless they were unable to perform respiratory function tests (usually $<6$ years old), had bronchospasm as a principal feature of their respiratory exacerbation, were thought to have allergic bronchopulmonary aspergillosis likely to require treatment with corticosteroids, or were likely to have a general anaesthetic during the study period. The ability to expectorate sputum was not a criterion for entry into the study.

All patients received a standard treatment protocol, ${ }^{8}$ including intravenous antibiotics (based on bacterial sensitivities), physiotherapy, bronchodilators, and nutritional advice from the time of admission.

Informed consent for the study was obtained from patients and parents on the day of admission. Stratified randomisation was used to improve the comparability of the groups. Patients were allocated a consecutive trial code number within four strata, based on age $(<$ or $\geqslant 12$ years) and forced vital capacity ( $<$ or $\geqslant 75 \%$ of predicted). Based on these codes the pharmacy department at St James's University Hospital referred to a randomised treatment plan and dispensed either amiloride hydrochloride nebuliser solution or placebo. The randomisation schedule was compiled by the study group statistician (TAS) and supplied confidentially to the pharmacy department. Both the patients and the remaining investigators were blinded to the treatment allocation.

The amiloride hydrochloride solution $5 \times 10^{-3} \mathrm{M}(0.15 \% \mathrm{w} / \mathrm{v})$ in $0.3 \%$ saline (approximately:pH $7 \cdot 0$ ) was prepared by the pharmacy department from amiloride hydrochloride powder (Cox Pharmaceuticals). The placebo used was $0.3 \%$ saline solution which had the same osmolality as the amiloride solution. The solutions were supplied as individual doses in identical darkened glass bottles which were stored at room temperature. All patients received $4.0 \mathrm{ml}$ three times daily. The solutions were nebulised using a Medix Maxi III compressor and a System 22 nebuliser (Medic-Aid) with a mouthpiece. Treatment was continued for the duration of 


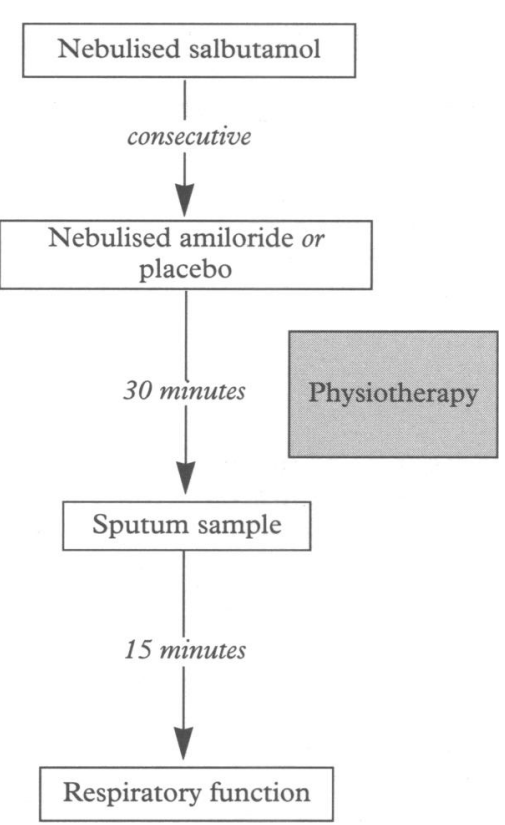

Monitoring of progress.

the inpatient treatment course (usually two weeks).

\section{MONITORING OF PROGRESS}

Baseline measurements of respiratory function, clinical score (see below), and sputum purulence and viscoelasticity were made on the morning after admission, before starting amiloride or placebo therapy. Respiratory function was also measured before and after the first dose of amiloride or placebo to ensure that bronchospasm did not occur.

Respiratory function was measured daily, 45 minutes after the administration of amiloride or placebo (during which time the patient received physiotherapy, see the figure), using a Micro spirometer (Micro Medical). Measurements of forced expiratory volume in one second $\left(\mathrm{FEV}_{1}\right)$ and forced vital capacity (FVC) were expressed as a percentage of expected values according to age, height, and sex.

A composite clinical score (assessed on cough, sputum volume and colour, respiratory rate, pulse rate, and presence of added sounds on chest auscultation) was also recorded daily. Each variable was scored $0-3$ and the sum noted. ${ }^{8}$

Sputum samples were collected twice weekly when possible. Purulence was estimated by simple grading colour against a reference chart

Table 1 Patients' baseline data

\begin{tabular}{|c|c|c|c|c|c|}
\hline & \multicolumn{2}{|c|}{ Amiloride $(n=13)$} & \multicolumn{2}{|c|}{ Placebo $(n=14)$} & \multirow[b]{2}{*}{$p$ Value } \\
\hline & Mean & Range & Mean & Range & \\
\hline $\begin{array}{l}\text { Age (years) } \\
\text { Male (number }(\%) \text { ) }\end{array}$ & $\begin{array}{l}13 \cdot 8 \\
6(46)\end{array}$ & $7 \cdot 9-27 \cdot 7$ & $\begin{array}{l}11 \cdot 8 \\
5(36)\end{array}$ & $6 \cdot 0-21 \cdot 1$ & $\begin{array}{l}0.3 \\
0.2\end{array}$ \\
\hline Weight (kg) & $36 \cdot 2$ & $20 \cdot 5-62 \cdot 1$ & $33 \cdot 3$ & $20 \cdot 1-55 \cdot 9$ & 0.6 \\
\hline Weight/height (\% predicted) & 92.6 & $74 \cdot 0-111 \cdot 6$ & 90.9 & $69 \cdot 7-112 \cdot 0$ & 0.7 \\
\hline $\mathrm{FEV}_{1}$ (\% predicted) & $52 \cdot 8$ & $13 \cdot 0-88 \cdot 0$ & 55.9 & $21 \cdot 0-111 \cdot 0$ & 0.8 \\
\hline FVC (\% predicted) & $63 \cdot 5$ & $12 \cdot 0-102 \cdot 0$ & $64 \cdot 1$ & $23 \cdot 0-114 \cdot 0$ & $1 \cdot 0$ \\
\hline Clinical score & 7.9 & $4 \cdot 0-15 \cdot 0$ & $7 \cdot 4$ & $2 \cdot 0-13 \cdot 0$ & 0.8 \\
\hline $\operatorname{IgG}(\mathrm{g} / \mathrm{l})$ & 13.9 & $9 \cdot 3-25 \cdot 4$ & $14 \cdot 5$ & $5 \cdot 4-26 \cdot 7$ & 0.8 \\
\hline \multirow{2}{*}{$\begin{array}{l}\text { Sputum purulence } \\
\text { Sputum viscoelasticity } \\
\left(\mathrm{G}^{\prime} \text { at } 10 \mathrm{~Hz}\right)\left(\mathrm{N} / \mathrm{m}^{2}\right)\end{array}$} & 2.5 & $2-3$ & $2 \cdot 2$ & $1-3$ & 0.4 \\
\hline & $18 \cdot 6$ & $4 \cdot 3-47 \cdot 0$ & $13 \cdot 5$ & $2 \cdot 5-33 \cdot 2$ & 0.4 \\
\hline
\end{tabular}

and was scored 0-3. Sputum samples for viscoelasticity measurement were snap frozen in liquid nitrogen and stored in a refrigerator. They were later transported on dry ice to the University of Brighton. Dynamic storage modulus $\left(G^{\prime}\right)$ and loss modulus $\left(G^{\prime \prime}\right)$ were measured using a Carri-med controlled stress rheometer, using a cone and plate geometry, a high sensitivity transducer, and oscillatory testing within the linear viscoelastic region in the range $1-10 \mathrm{~Hz}^{9}$

The study protocol was approved by the research ethics committee for the two hospitals.

\section{STATISTICAL METHODS}

Estimates of the study sample size required were undertaken and it was calculated that 36 patients in each treatment group would be required to detect a $10 \%$ additional increase in FVC (percentage predicted), with an $80 \%$ power at a 5\% significance level. However, we believed that it was more likely that amiloride would result in an increased rate in improvement, rather than an augmentation in the increase in respiratory function which might be achieved by a course of intravenous antibiotics. It was for this reason that these data were measured daily.

Data were analysed on a personal computer using the SPSS/PC + software package. The repeated measurements of $\mathrm{FEV}_{1}, \mathrm{FVC}$, and clinical score were averaged over three time periods. The means and medians of these were compared by unpaired $t$ tests or MannWhitney $U$ tests respectively. Multivariate analysis of variance (MANOVA) was also used to compare these variables in order to take account of correlation of serial measurements over time. ${ }^{10}$ In addition a comparison of the time to peak lung function reading was carried out which is also an appropriate method for analysing serial measurements on the same patients. $^{11}$

\section{Results}

\section{PATIENTS}

Twenty seven patients (mean age 12.8 years (range $6 \cdot 0-27 \cdot 7$ years), 11 males, 16 females) were recruited into the study. The groups were

Table 2 Sputum bacteriology (number of patients)

\begin{tabular}{lll}
\hline & Amiloride & Placebo \\
\hline Pseudomonas aeruginosa & 7 & 9 \\
Burkholderia cepacia & 1 & 0 \\
Stenotrophomonas maltophilia & 1 & 2 \\
Staphylococus aureus & 4 & 4 \\
Haemophilus infuenzae & 2 & 2 \\
Aspergillus fumigatus & 2 & 3
\end{tabular}

Table 3 Antibiotic treatment (number of patients)

\begin{tabular}{lrc}
\hline & Amiloride & Placebo \\
\hline Ceftazidime & 5 & 6 \\
Ureidopenicillins (pipericillin, azlocillin) & 9 & 5 \\
Aminoglycosides (tobramycin, amikacin) & 11 & 12 \\
Colomycin (IV) & 2 & 2 \\
Ciprofloxacin (oral) & 2 & 2 \\
Others (temocillin, imipenen, aztreonam, & \multicolumn{1}{c}{6} & 2. \\
\hline cefotaxime, ampicillin) & 6 &
\end{tabular}


Table 4 Differences between respiratory function values at the three time periods

\begin{tabular}{|c|c|c|c|c|c|c|c|c|c|}
\hline \multirow{2}{*}{$\begin{array}{l}\text { Time } \\
\text { period }\end{array}$} & \multirow{2}{*}{$\begin{array}{l}\text { No } \\
(A m / P l)\end{array}$} & \multicolumn{4}{|c|}{ Mean $F E V_{1}(\%$ predicted) } & \multicolumn{4}{|c|}{ Mean FVC (\% predicted) } \\
\hline & & Amiloride & Placebo & Difference $(95 \%$ CI) & p Value $\ddagger$ & Amiloride & Placebo & Difference $(95 \% C I)$ & $p$ Value $\ddagger$ \\
\hline $\begin{array}{l}Q 1 \\
Q 2 \\
Q 3\end{array}$ & $\begin{array}{c}13 / 14 \\
12 / 14 \\
9 / 9\end{array}$ & $\begin{array}{l}55 \cdot 5 \\
59 \\
57 \cdot 5\end{array}$ & $\begin{array}{l}59 \\
64 \\
62\end{array}$ & $\begin{array}{l}3.3(-23.3 \text { to } 16.6) \\
4.8(-24.0 \text { to } 14.4) \\
4.4(-27.9 \text { to } 19.0)\end{array}$ & $\begin{array}{l}0 \cdot 7 \\
0 \cdot 6 \\
0 \cdot 86\end{array}$ & $\begin{array}{l}69 \\
74 \\
69\end{array}$ & $\begin{array}{l}67 \\
73 \\
71\end{array}$ & $\begin{array}{r}-1 \cdot 8(-15.6 \text { to } 4 \cdot 2) \\
-0.5(-19 \cdot 8 \text { to } 23.5) \\
2 \cdot 1(-20 \cdot 1 \text { to } 21 \cdot 1)\end{array}$ & $\begin{array}{l}0 \cdot 7 \\
1 \cdot 0 \\
0 \cdot 85\end{array}$ \\
\hline
\end{tabular}

$\mathrm{CI}=$ confidence interval; $\mathrm{FEV}_{1}=$ forced expiratory volume in one second $\mathrm{FVC}=$ forced vital capacity; $\mathrm{Am}=$ amiloride; $\mathrm{Pl}=\mathrm{placebo}$. ‡Unpaired $t$ test.

comparable with respect to age, anthropometry, baseline respiratory function, clinical score, ${ }^{8}$ and serum immunoglobulin $\mathrm{G}$ concentration (table 1). Sputum viscoelasticity and purulence were comparable between the groups at baseline (table 1); however, insufficient data were collected during the trial to use these variables to assess the efficacy of amiloride. There were no material differences in the patients' sputum bacteriology (table 2) or the antibiotics received (table 3 ) between the two groups.

Twenty two patients completed the study. Five patients did not complete the study protocol: two patients in the amiloride treatment group developed bronchospasm and were withdrawn from the study; the others were in the placebo group. Of these three patients, one developed chickenpox, one elected to withdraw from the study without giving a reason, and a third was withdrawn because of noncompliance with the study protocol.

RESPIRATORY FUNCTION AND CLINICAL SCORE The repeated measurements of these data were averaged over three time periods; the first four days $(Q 1)$, the second five days $(Q 2)$, and the final six days $(Q 3)$. There was no difference between the two arms of the study for mean $\mathrm{FEV}_{1}$ or FVC in any of the three time periods (table 4). Non-parametric analysis of medians showed similar results. A number of patients were discharged between periods $Q 2$ and $Q 3$, and thus $Q 3$ contained a biased selection of patients who had made less improvement. This explains the reduction in average respiratory function between periods $Q 2$ and $Q 3$.

MANOVA for repeated measures showed a significant increase in the $\mathrm{FEV}_{1}(\mathrm{p}=0.006)$ and FVC $(p=0.003)$ over the three time periods ( $\chi^{2}$ test). However, there was no significant difference between the trend of improvement between the treatment and control group $\left(\mathrm{FEV}_{1} \mathrm{p}=0.8 ; \mathrm{FVC} \mathrm{p}=0 \cdot 7\right)$. This was unlikely to be the result of a lack of power in the study. The time to peak $\mathrm{FEV}_{1}$ and FVC for each patient was determined (table 5). There was a small but statistically significant reduction in time to peak FVC in the amiloride group. Patients who withdrew from the study were included in the estimates of time to peak

Table 5 Time to peak respiratory function

\begin{tabular}{lllll}
\hline & $\begin{array}{l}\text { Amiloride } \\
(n=13)\end{array}$ & $\begin{array}{l}\text { Placebo } \\
(n=14)\end{array}$ & $\begin{array}{l}\text { Difference } \\
(95 \% \text { CI })\end{array}$ & p Value* \\
\hline Time to peak FEV F (mean No of days) $_{1}$ & $5 \cdot 7$ & $7 \cdot 9$ & $-2 \cdot 2(-5.6$ to $1 \cdot 2)$ & $0 \cdot 19$ \\
Time to peak FVC (mean No of days) & $4 \cdot 2$ & $7 \cdot 6$ & $-3.4(-6.4$ to -0.4$)$ & 0.026 \\
\hline
\end{tabular}

`Two sample $t$ test. respiratory function; however, the difference in the time to peak FVC was still statistically significant even if these subjects were excluded from the analysis.

There was no difference in clinical score at each of the three time periods. MANOVA again showed a significant improvement over time $(p<0.001)$, but no difference between the groups $(p=0 \cdot 8)$. There were no significant changes in serum sodium or potassium in either group.

\section{Discussion}

Nebulised amiloride has been found to improve cough clearance and mucociliary clearance in cystic fibrosis patients, ${ }^{45}$ and other studies have shown that it can increase the quantity of sputum expectorated. ${ }^{12} 13 \mathrm{It}$ has antibacterial activity against pseudomonas species $^{14}$ and synergy with tobramycin against Burkholderia (formerly Pseudomonas) cepacia. ${ }^{15}$ For these reasons we postulated that nebulised amiloride may be of benefit when used in the treatment of acute respiratory exacerbations.

Most patients are returned to their 'best' clinical condition by a course of intravenous antibiotics. We predicted that any benefit of additional amiloride would be to increase the rate of improvement in respiratory function, rather than its extent, but this made pretrial estimates of the required study sample size more difficult to determine. However, there was a considerable increase in the use of home intravenous antibiotic treatment during the period in which the study was conducted, and significantly fewer patients than planned for were recruited. This reduced the power of the study to detect differences as statistically significant, and thus the study should be considered as generating a hypothesis rather than proving one.

We have shown that the additional use of nebulised amiloride in cystic fibrosis patients receiving a standard inpatient intravenous antibiotic course did not result in a greater improvement in respiratory function or clinical score than nebulised vehicle alone. However, there was a suggestion that nebulised amiloride may shorten the time to achieve optimal respiratory function (for FVC), which may have implications for the total duration of intravenous antibiotic treatment needed. We believe that these results warrant confirmation in a larger multicentre study.

\section{CONCLUSION}

We conclude that nebulised amiloride may be of some benefit to cystic fibrosis patients in 
accelerating the rate of recovery of lung function. However, its place as part of a new generation of specific therapy cystic fibrosis remains to be determined. A recent study has shown that the effect of amiloride may be augmented by the additional use of uridine triphosphate. ${ }^{16}$ Future studies should consider evaluation of this combination therapy.

We are grateful to the Cystic Fibrosis Trust for funding IMB.

1 Boucher RC, Stutts MJ, Knowles MR, Cantley L, Gatzy JT $\mathrm{Na}^{+}$transport in cystic fibrosis respiratory epithelia. Abnormal basal rate and response to adenylate cyclase activation. $\mathcal{F}$ Clin Invest 1986; 78: 1245-5

2 Boucher RC, Cotton CU, Gatzy JT, Knowles MR Yankaskas JR. Evidence for reduced $\mathrm{Cl}^{-}$permeability and increased $\mathrm{Na}^{+}$permeability in cystic fibrosis human primary cell cultures. F Physiol (Lond) 1988; 405: 77-103

3 Knowles MR, Gatzy JT, Boucher RC. Increased bioelectric potential difference across respiratory epithelia in cystic fibrosis. N Engl f Med 1981; 305: 1489-95.

4 Köhler D, App E, Schmitz-Schumann M, Würtemburger $G$, Matthys H. Inhalation of amiloride improves mucociliary and cough clearance in patients with cystic fibrosis. Eur f Respir Dis 1986; 69 (suppl 146): 319-26.

5 App E, King M, Helferieder R, Köhler D, Matthys H. Acute and long-term amiloride inhalation in cystic fibrosis lung and long-term amiloride inhalation in cystic fibrosis lung
disease. A rational approach to cystic fibrosis therapy. Am Rev Respir Dis 1990; 141: 605-12.

6 Knowles MR, Church NL, Waltner WE, et al. A pilot study of aerosolized amiloride for the treatment of lung disease in cystic fibrosis. $N$ Engl $\mathcal{F}$ Med 1990; 322: 1189-94.

7 Graham A, Hasani A, Alton EWFW, et al. No added benefit from nebulized amiloride in patients with cystic fibrosis. Eur Respir f 1993; 6: 1243-8.

8 Conway SP, Miller MG, Ramsden C, Littlewood JM. Intensive treatment of pseudomonas chest infection in cystic fibrosis: a comparison of tobramycin and ticarcillin and netilmicin and ticarcillin. Acta Paediatr Scand 1985; 74: 107-13.

9 El-Hariri LM, Martin GP, Marriott C. The effect of sodium taurodeoxycholate on the rheological properties of pig
native and purified gastric mucus [Abstract]. $\mathcal{f}$ Pharmacol 1989; 41: 75P.

10 Altman DG. Practical statistics for medical research. London: Chapman and Hall, 1991: chapter 12.

11 Matthews NN, Altman DG, Campbell MJ, Royston P. Analysis of serial measurements in medical research. BMF 1990; 300: $230-5$

12 Lindemann H, Becker T, Bittner P, Boldt A, Hofmann T, Schwandt HJ. Elimination of secretions in CF patients under amiloride inhalation. [In German.] Pneumologie 1990; 44: 1148-50

13 Riedler J, Huttegger I. Pilot study of amiloride inhalation in children with cystic fibrosis. [In German.] Klin Padiat 1992; 204: 158-62

14 Cohn RC, Rudzienski L, Putnam RW. In vitro antimicrobial activity of amiloride analogs against pseudomonas. Chemotherapy 1992; 38: 232-7.

15 Cohn RC, Jacobs M, Aronoff SC. In vitro activity of amiloride combined with tobramycin against pseudomonas isolates from patients with cystic fibrosis. Antimicrob Agents Chemother 1988; 32: 395-6.

16 Knowles MR, Clarke LL, Boucher RC. Activation by extracellular nucleotides of chloride secretion in the airway epithelial of patients with cystic fibrosis. $N$ Engl $f$ Med 1991; 325: 533-8. 